\title{
Abbott's Fluorescence Polarization Immunoassay for Cyclosporine and Metabolites Compared with the Sandoz "Sandimmune" RIA
}

\author{
Ajit Sanghvi,' Warren Diven,' Howard Seltman, ${ }^{1}$ and Thomas Starzl'
}

A new procedure for measuring cyclosporine in plasma has been introduced by Abbott Laboratories, involving their TDx instrumentation and fluorescence polarization immunoassay. Radioimmunoassay (RIA) and high-performance liquid chromatography are currently the conventional methods for measuring cyclosporine in plasma and whole blood. In an effort to find a method that will decrease the radioactive hazard, the reagent and supply cost, and the labor requirements associated with RIA procedures, we used specimens from transplantation patients to compare the Abbott assay with the Sandoz Sandimmune assay. We believe that the Abbott assay offers some advantages over the Sandimmune RIA procedure, providing a reliable but simpler and less hazardous technology.

The increase in organ transplantation and in patients receiving cyclosporine as part of immunosuppressive therapy has caused a dramatic increase in the number of laboratory requests for its assay (1). The two technologies commonly used to evaluate cyclosporine are high-performance liquid chromatography (HPLC) and radioimmunoassay (RIA). Abbott Laboratories has recently introduced an assay that measures cyclosporine and its metabolites by fluorescence polarization immunoassay (FPLA), with the "TDx" instrumentation (2).

At the University of Pittsburgh School of Medicine, 4000 patients' specimens per month are analyzed in duplicate by the Sandoz "Sandimmune" assay for cyclosporine. The method measures the drug and some fraction of metabolites in either plasma or whole blood. A competitive proteinbinding ligand procedure, the Sandimmune RIA involves use of a tritiated antigen, which requires liquid scintillation spectrometry. The combination of radiolabeled materials and complex analytical techniques results in a variety of practical concerns: $(a)$ radioactive hazard to personnel; $(b)$ disposal of low-level radioactive waste; (c) expense and storage of reagents and disposables; $(d)$ need for highly trained technical staff; $(e)$ increased labor intensity from multiple handling steps; $(f)$ lengthy incubation and counting processes; ( $g$ ) complex and costly instrumentation, requiring significant space accommodations; and $(h)$ relatively poor precision.

As the volume of cyclosporine analyses increases, the difficulties encountered in RIA procedures are magnified. We have evaluated the Abbott cyclosporine assay in order to more quickly provide results to clinicians and also to eliminate radioactive reagents from the laboratory. We analyzed 408 specimens along with more than 200 controls, in duplicate, by both the Abbott FPLA TDx method and the Sandim. mune RIA. Results of this study indicate that values for cyclosporine measured by the FPIA TDx are higher than those determined by the Sandimmune RIA. The TDx meth-

Departments of ${ }^{1}$ Pathology and 2 Surgery, School of Medicine, University of Pittsburgh, Pittsburgh, PA 15261.

Received December 30, 1987; accepted May 16, 1988. od, however, is more precise, easier, and highly reliable. In addition to rapid result reporting, the method provides a simple technology with few handling steps, compact instrumentation, and few reagent storage and disposal problems.

\section{Materials and Methods}

Sample collection. Samples, collected from each patient into tubes containing EDTA as anticoagulant, were allowed to equilibrate for $2 \mathrm{~h}$ at room temperature, then plasma was separated from the cells at room temperature after centrifugation. Temperature of the specimen during separation is an important factor, because the equilibration of cyclosporine with erythrocytes is temperature dependent (3). No correction was made for hematocrit.

\section{Procedures}

$R I A$. Cyclosporine in plasma was measured by RIA with the Sandoz RIA kit according to the manufacturer's instructions (4).

FPIA. Fluorescent polarization immunoassay with use of the Abbott TDx instrument is a recognized method for measurement of drugs and other constituents in body fluids $(5-7)$. In the new procedure for cyclosporine, an anti' ty is used that reacts both with cyclosporine and some of its metabolites. We performed the assay according to the manufacturer's instructions.

The concentration range of the Abbott calibrators is 0 to $1000 \mu \mathrm{g} / \mathrm{L}$. Specimens containing cyclosporine in concentrations $>1000 \mu \mathrm{g} / \mathrm{L}$ were diluted with the zero calibrator (normal human serum) before the precipitation step, as were also specimens with background intensity $>1000$. The manufacturer does not recommend a change in the background (MX BKG) setting.

\section{Results}

Cross-reactivity and s cificity. We tested cross-reactivity with compounds listed in Table 1 , whose concurrent use might interfere with the assay. Cross-reactivity was established for a specimen by adding the test compound, at a concentration of $100 \mathrm{mg} / \mathrm{L}$, to drug-free pooled human serum, then assaying the specimen by the FPLA assay. The percentage cross-reactivity was calculated as: (measured cyclosporine and metabolites concentration divided by the concentration of the test compound) $\times 100$. The compounds tested were all below the detection limit of the assay $(<15$ $\mu \mathrm{g} / \mathrm{L})$.

Precision. Precision studies were performed on the Abbott low-, medium-, and high-concentration control sera (Table 2). All three control concentrations were included in each batch of $2^{n}$. For the low control, 59 replicates were processed, yielding a coefficient of variation (CV) of $9.5 \%$ total and $7.4 \%$ within-run; for the medium concentration, 60 replicates for a total $\mathrm{CV}$ of $4.9 \%$ and within-run $\mathrm{CV}$ of $2.9 \%$; for the high concentration, 61 replicates with a total $C V$ of $4.4 \%$ and within-run CV of $3.0 \%$.

Precision of patients'-sample and control duplicates was excellent. Of about 600 specimens analyzed, only 10 samples 
Table 1. Compounds Tested for Interference in the Abbott Cyclosporine Assay

Amikacin

Ampicillin

Azathioprine

Carbamazepine

Cephalosporin

Chloramphenicol

Cimetidine

Digitoxin

Digoxin

Dipyridamole

Disopyramide

Encainide

Erythromycin

Ethosuximide

Furosemide

Gentamicin

Kanamycin A

Kanamycin B

Ketoconazole

Lidocaine

- These compounds were undetectable $(<15 \mu \mathrm{g} / \mathrm{L}$ ) when tested up to 100 or $\cdot 10 \mathrm{mg} / \mathrm{L}$.

Table 2. Performance Statistics of the TDX Cyclosporine Assay

\begin{tabular}{|c|c|c|c|c|}
\hline \multirow{3}{*}{$\begin{array}{l}\text { Control } \\
\text { (Abbott) }\end{array}$} & \multirow{2}{*}{$\begin{array}{c}\text { Expected } \\
\text { range }\end{array}$} & \multirow{2}{*}{$\begin{array}{c}\text { Determined } \\
\text { range }\end{array}$} & \multicolumn{2}{|c|}{$\begin{array}{c}\text { Precision } \\
(n=59 \text { to } 61)\end{array}$} \\
\hline & & & \multirow{2}{*}{$\begin{array}{l}\text { Total } \\
\text { CV, \% }\end{array}$} & \multirow{2}{*}{$\begin{array}{c}\text { Within-run } \\
\text { CV, \% }\end{array}$} \\
\hline & \multicolumn{2}{|c|}{ mg/l } & & \\
\hline $\begin{array}{l}\text { Low concn } \\
\text { Med. concn } \\
\text { High concn }\end{array}$ & $\begin{array}{c}60-90 \\
225-275 \\
600-800\end{array}$ & $\begin{array}{c}63-93 \\
219-267 \\
663-792\end{array}$ & $\begin{array}{l}9.5 \\
4.9 \\
4.4\end{array}$ & $\begin{array}{l}7.4 \\
2.9 \\
3.0\end{array}$ \\
\hline
\end{tabular}

had to be repeated because of duplication problems (duplication criterion: samples must duplicate within 5 net Polarization Units)

Standard-curve stability. Three times during 20 days, fresh TDx standards were run in the TDx. Values consistently fell within $5 \%$ of assigned values and none differed by more than $10 \%$.

Carryover. We saw no significant carryover from specimens with high concentrations.

Accuracy. Analytical recovery was tested with two sets of samples prepared by adding cyclosporine to give concentrations of $50,75,100,200,250,500$, and $700 \mu \mathrm{g} / \mathrm{L}$ to normal human serum and to normal human serum diluted fivefold in TDx Dilution Buffer. The TDx analyzer was calibrated with serum-based calibrators provided by the manufacturer. Both sets of specimens were determined in replicates of five and the results compared with the calibration curve (Table 3 ). The average analytical recovery from diluted serum was $98.5 \%$ (SD 3.1\%), from undiluted serum, 97.2\% (SD 3.8\%).

Comparison of methods. We received 408 specimens with requests for cyclosporine assays. These were used in the correlation studies. Plasma samples were prepared and processed by both the Sandoz Sandimmune RIA procedure and Abbott's cyclosporine and metabolites FPIA assay. Each sample was analyzed in duplicate and the values were averaged. On linear regression analysis comparing the two sets of results, the equation for the regression line was determined to be $(1.72 \pm 0.045 x)+(61.8 \pm 4.48) \mu \mathrm{g} / \mathrm{L}$, with a correlation coefficient of $r=0.884$ (Figure 1). The standard error of the regression was 56.4.
Table 3. Analytical Recovery of Cyclosporine in the Abbott TDx Assay

\begin{tabular}{|c|c|c|c|c|}
\hline \multirow[t]{2}{*}{$\begin{array}{c}\text { Expected } \\
\text { concn }\end{array}$} & \multirow{2}{*}{$\begin{array}{l}\begin{array}{c}\text { Recovered from } \\
\text { diluted serum }\end{array} \\
\mu \mathrm{g} L\end{array}$} & \multirow[b]{2}{*}{ Recovery, $\%$} & \multicolumn{2}{|c|}{$\begin{array}{c}\text { Recovered from } \\
\text { undil. serum }\end{array}$} \\
\hline & & & $\mu g / L$ & $\%$ \\
\hline 50 & 50.40 & 100.80 & 49.79 & 99.58 \\
\hline 75 & 75.15 & 100.20 & 71.39 & 95.19 \\
\hline 100 & 96.64 & 96.64 & 96.41 & 96.41 \\
\hline 200 & 197.53 & 87.77 & 202.98 & 101.49 \\
\hline 250 & 257.75 & 103.10 & 254.09 & 101.64 \\
\hline 500 & 479.50 & 95.90 & 459.79 & 91.96 \\
\hline 700 & 660.43 & 94.35 & 657.32 & 93.90 \\
\hline
\end{tabular}

\section{Discussion}

We found the Abbott TDx to be significantly more precise than the Sandimmune RIA. Coefficients of variation ranged from $4 \%$ to $10 \%$ for the TDx. Comparable values for the Sandimmune assay, which is in routine use in our laboratory, are $10 \%$ to $17 \%$.

When our HPLC or RIA standards were run in the TDx, the regression equation resulting from that comparison was $\mathrm{TDx}$ value $=0.92[\mathrm{HPLC}$ or RIA] value $-3.9, r=0.9992$. However, values for the TDx assay from patients' samples were about 1.7 times the RIA values. This lack of correlation indicates that the two assays are not in fact measuring exactly the same thing. The Abbott antibody may react with a cyclosporine metabolite that is unreactive in the Sandoz assay system, or there may be a generally increased crossreactivity to all or to some subset of cyclosporine metabolites. In either case we believe this offers an advantage for the TDx assay, because recent observations from this insti-

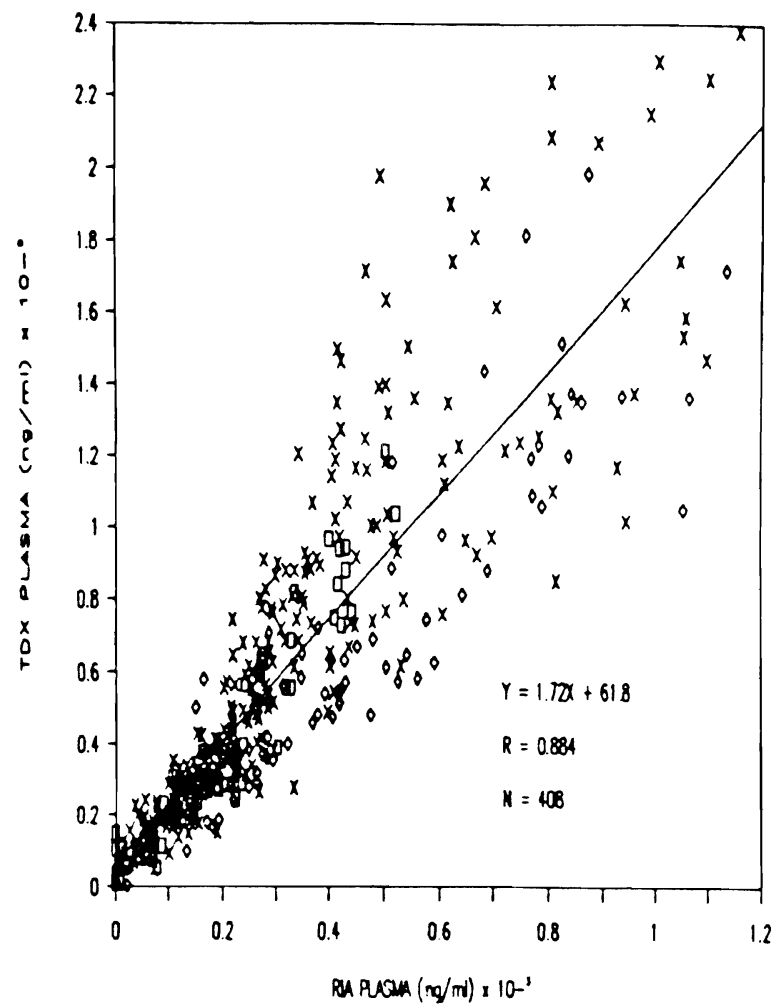

Fig. 1. Comparison of cyclosporine values obtained by the Abbott TDX and Sandoz RIA methods

Organ transplanted is as indicated: $\times$, liver, $\square$, heart, $\diamond$, kidney 
fution milumb that anme cyclosporine metabolites-particularly MI. MI:, MI7. M18, and M21-possess immunosuppresiln achify as demonstrated in vitro by use of lymphochemifivalinil asciass. Metabolites M17 and M1 in purficulne "hhlin immunosuppressive activity in vitro apmichink that mutuced by cyclosporine. Moreover, these

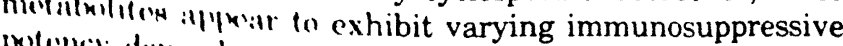

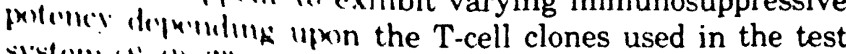

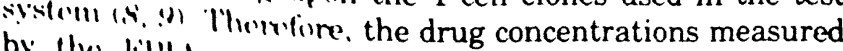
hy the lillis aswiy may more closely approximate the cinconlliflin if immunosuppressive drug present in the circulılıII 'lhiso differences between the two assay syswith the till will the fact that there is greater imprecision with thI IRI:I metherd, account for the observed correlation corflicinf if (I) isit as well as the greater scatter observed at

There nw I wn pentential problems with the TDx plasma

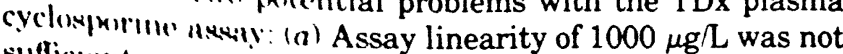
suflici'nt III "III I alx)ratory because about four to six samples III II (1'il of ' 2() needed to be diluted. $(b)$ With prolonged use. the inf "hirlly of the kit may be compromised because,

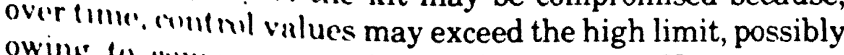
owing l1 som. "vinporation of the reagent. However, we ohservint 111 suliwfintial evaporation during an analytical run: (rmlinl valucs at the beginning and end of several assuys wim $2.47: 9.6$ and $243 \pm 9.4 \mathrm{mg} / \mathrm{L}(\mathrm{n}=24)$, (t)ively

'The 'Tl) methed offers a simpler procedure with fewer handling slipis and faster turnaround time. The instrumentution is mulumilen and compact, allowing better use of technologist time and laboratory space. Reagents and supplies present minimal storage and disposal problems and no radioactivity hazand.

References

1. Sanghvi A. Impact of organ transplant program on the clinical chemistry laboratory at the University of Pittsburgh. Arch Pathol Lab Med 1986;110:95-7.

2. Immunosuppressant Drug Assay: TDx Cyclosporine and Metabolites. Package insert dated 4/13/87. North Chicago, IL: Abbott Laboratories.

3. Van den Berg JW. Verhof ML, De Boes AJ, Schalm SW. Cyclosporin A assay: conditions for sampling and processing of blood. Clin Chim Acta 1985;147:291-7.

4. Cyclosporin RIA-KIT. Instructions for the determination of cyclosporin concentrations in blood, or plasma, or serum. 5th ed. (revised August 1986). Basle, Switzerland: Sandoz Ltd.

5. Popelka SR, Miller DM, Holen JT, Kelso DM. Fluorescence polarization immunoassay II analyzer for the rapid, precise measurement of fluorescence polarization with use of disposable cuvettes. Clin Chem 1981;27:1198-201.

6. Blecka LJ, Jackson GJ. Immunoassays in therapeutic drug monitoring. Clinics Lab Med 1987;7:357-69.

7. Jolley ME, Stroupe SD, Schwenzer CJ, et al. Fluorescence polarization immunoassay. III. An automated system for therapeutic drug determination. Clin Chem 1981;27:1575-9.

8. Zeevi A, Venkatramanan R, Burckart G, et al. Sensitivity of activated human lymphocytes to cyclosporine and its metabolites. Hum Immunol, in press.

9. Zeevi A, Erias G, Burckart G, et al. Immunosuppressive effect of cyclosporine metabolites from human bile on alloreactive $T$ cells. Transplant Proc, in press. 